\title{
25 Research Square \\ Effect of Frequency Magnetic field on Gram Positive and Gram Negative Bacteria
}

\author{
Mohamad Reza Bayatiani \\ Arak University of Medical Sciences \\ fatemeh seif ( $\nabla$ sahar_s59@yahoo.com ) \\ mohamad Arjomandzadegan \\ Arak University of Medical Sciences \\ alireza moradabadi \\ Arak University of Medical Sciences \\ arash parvin \\ Arak University of Medical Sciences
}

\section{Research note}

Keywords: Frequency magnetic field, bacteria growth, gram-positive bacteria, gram-negative bacteria

Posted Date: October 11th, 2019

DOI: https://doi.org/10.21203/rs.2.15685/v1

License: (c) (i) This work is licensed under a Creative Commons Attribution 4.0 International License.

Read Full License 


\section{Abstract}

Objective It is necessary to evaluate the harmful or useful effects of electromagnetic waves on living organisms and determine the threshold of these radiations. In this research, the effect of magnetic fields on the growth of gram-positive ( Staphylococcus aureus) and gram-negative (Escherichia coli ) bacteria has been evaluated.

Results In Gram-negative bacteria such as E. coli in both magnetic fields $1 \mathrm{mT}$ and $2 \mathrm{mT}$ at different frequencies, an additive effect was seen on the growth of bacteria. When the frequency increased the trend of increasing bacterial growth, slowed. In Gram-positive bacteria such as Staphylococcus, this effect was less. In $1 \mathrm{mT}$ magnetic field, the growth of bacteria was seen but the $2 \mathrm{mT}$ field was virtually ineffective and the differences between two groups at different frequencies were not significant. Also, significant changes didn't observe with increasing frequency. Study of bacterial growth in terms of frequency in both case and control groups showed an increasing trend. With increasing frequency from $50 \mathrm{~Hz}$ to $150 \mathrm{~Hz}$ significantly increased the rate of bacterial growth and the growth in the higher frequencies more than lower frequencies. Magnetic field had increment effect on the growth of bacteria. This effect was greater on gram-negative than on gram-positive.

\section{Introduction}

Today's use of electrical devices has a wide role in human life. Electromagnetic fields, similar to those found in overhead power lines and other electrical devices can have a biological effect. The effects of electromagnetic fields on living organisms have been a subject of active investigation these years. In the past two decades' people have concerns about the potential harm of exposure to Low-Frequency Magnetic Fields (ELF-EMF) with frequencies below $300 \mathrm{~Hz}$ that is common in the human environment. Some studies have been established to verify the effects of ELF-EMF on cell functions $(1,2)$. The effect of ELF-EMF has also been evaluated on bacteria in the studies (3-5). The results have been showed that ELF-EMF can negatively $(6,7)$ or positively $(8,9)$ effect on the living systems functions and bacteria antibiotic sensitivity, so some results are in contrast with each other. The previous studies have shown that the effects of ELF-EMF are depending on some parameters such as frequency and intensity of the field, time of exposure and type of bacteria cells. But due to the complexity of biological systems, there is not the final agreement on the effect of ELF on bacteria as a living system(10). So it seems that more investigation about this subject is necessary. In this work, the effect of ELF-EMF exposure on bacteria growth by changing these parameters: frequency $(50,75,100$ and $150 \mathrm{~Hz})$, magnetic field ( 1 and $2 \mathrm{mT})$ and type of bacteria (gram positive and gram negative) have been investigated.

\section{Methods}

\section{Electromagnetic generation system:}


Electromagnetic exposures were produced by our homemade electromagnetic generator (previous study) developed and set up in the department of medical physics of Arak University of Medical Sciences. The basic part of this system is consisting of a pair of Helmholtz coils by using power supply and signal generator (Fig 1).

This system has selection button that user can select desired frequency between 0 (as a static magnetic field) to $300 \mathrm{~Hz}$ (as a pulsating magnetic field) and it can produce magnetic fields with intensities from 0 to $8 \mathrm{mT}$. The efficiency and precision of the apparatus were checked by a gauss-meter. The uniformity of the electromagnetic field between the coils allowed simultaneous exposure to the cultures. This feature was in good agreement with the computation of the field distribution and homogeneity calculated by a Laplace equation simulation program, which takes into consideration the finite dimensions of coils. In this study, magnetic fields with frequencies $(50,75,100$ and $150 \mathrm{~Hz})$ and intensities of (1 and $2 \mathrm{mT})$ were used on two types of bacteria (gram positive and gram negative).

Table 1: The physical parameters

\begin{tabular}{ll} 
Physical parameters & properties \\
\hline Outer diameter & $54 \mathrm{~cm}$ \\
\hline Inductance & $3 \mathrm{mH}$ \\
\hline Resistance & $4.2 \Omega$ \\
\hline Number of turns & 48 \\
\hline Autotransformer & $2 \mathrm{KW}$ and $0-300 \mathrm{~V}$ \\
\hline Transformer & $2500 \mathrm{~W}$ and $12-220 \mathrm{~V}$
\end{tabular}

Strains: The bacterium used in this work was strains E. coli (ATCC 25922) and S. aureus (ATCC 25923) provided from the microbiological Lab, Medicine Faculty, Arak University of Medical Sciences. Standard biochemical tests such as Gram staining, coagulase, Dnase, production of catalase, and fermentation of mannitol were used for the identification of S. aureus. In order to confirm E. coli, in addition to Gram staining, biochemical tests such as lysine decarboxylase, motility, methyl red, indole, Voges-Proskauer, and, Simmons citrate test, ornithine decarboxylase and triple sugar iron were used.

The pour plate method for counting the number of colony-forming units: This method used for colony counting in a fixed amount of inoculum (generally $1 \mathrm{ml}$ ). In the present study, we used a dilution of 0.5 McFarland standards. We put the 1 millilitre diluted bacterial strain in an 8 centimeter sterile Petri dish and then Muller Hinton agar (approx. $20 \mathrm{~mL}$ ) poured into the Petri dish containing the bacterial dilution and mixed well. After incubation in $37^{\circ} \mathrm{C}$ the colony forming bacterial count and used the $(\mathrm{CFU} / \mathrm{mL}=\mathrm{CFU}$ * dilution factor * 1 /aliquot) formula to find $\mathrm{CFU} / \mathrm{mL}$. 
Setup for the treatment of the bacterial culture: we used serial dilution of the bacteria and they are exposed to the magnetic fields with different frequencies (50, 75, 100 and $150 \mathrm{~Hz})$. After that the bacteria cultured in the Muller Hinton agar (used Pour plate method to counting the number of colony-forming bacteria). The dilution prepared in the $1 \mathrm{ml}$ the whole mixture first we dispense 900 microliters in 7 tube and ac magnetic fields $(0.0-1.0 \mathrm{KHz})$ at the fixed intensity of the order of $450 \mathrm{mT}$ and were determined by a Hall effect probe Gaussmeter. The magnetic fields inside the solenoid were approximately homogenous in a region $\pm 3 \mathrm{~cm}$ off the center of the coil. The device was kept at $37^{\circ} \mathrm{C}$ in an incubator cabinet and it was measured by a thermometer. $S$. aureus (clinical strain) from the Laboratory Aníbal Zaidenberg of the Biology Department, of the Faculty of Science-LUZ, were used. Nutritive Broth (Merck, Darmstadt) and Plate Count Agar (Difco, Detroit) were used for cultivation of the bacteria. Salt solution $0.75 \%$ was used to make serial dilutions until $10^{-5}$. Fresh bacterial cultures were used throughout the experiments. Control cultures were kept in the same conditions as the exposed ones except for the sole exposition to the magnetic fields. The number of colony forming units (CFU) was used to quantify the results. The samples were placed first into glass tubes on a nonconductive stand (homemade) along the axis of the coil and then introduced inside to solenoid during exposure times from $0 \mathrm{~h}$ to $6 \mathrm{~h}$. In order to reduce the uncertainty in our measurements and to obtain reliable results, each test was performed independently up to 4 times keeping the same experimental conditions.

\section{Results}

The magnetic fields effect on the bacterium growth showed by colony forming unit on the Muller Hinton agar which cultured by pour plate method. The bacterium in the control dilution $\left(10^{-5}-10^{-7}\right.$ of 0.5 McFarland standards) has more $\mathrm{CFU} / \mathrm{mL}$ than the magnetic field bacterium. The $\mathrm{CFU} / \mathrm{mL}$ of the $10^{-5}$ and $10^{-6}$ of $0.5 \mathrm{McF}$ arland standards dilution of E.coli on the $50 \mathrm{~Hz}$ magnetic field was 27 and 12 respectively, while this amount for the control group was 720 and 480, respectively... Show the difference between the $\mathrm{CFU} / \mathrm{ml}$ were have grown on the pour plate method we used the logarithm of the CFU/ $\mathrm{ml}$. The logarithm on 10 bases made the minor change bigger it's better to find. Also, the difference between the $10^{-5}$ and $10^{-7}$ of $0.5 \mathrm{McF}$ arland standards dilution is big and the logarithm made this different small. On the other hand, the effect of the magnetic field on the bacterium growth is so small and the logarithm made this different big. The data analyzed and they have been shown on the figure2.

\section{Discussion}

Electrical devices have a major role in human life and their effects on different biological structures have been discussed in recent years. In this study, we investigated the effect of magnetic field intensity and different frequencies on bacteria. E. coli and S. aureus (gram negative and gram positive bacteria, respectively) were selected for this study. These two bacteria are found in abundance in nature, and in addition, they cause various infections, including diarrhea, wound infection and septicemia in humans. After placing $E$. coli in a magnetic field of $1 \mathrm{mT}$, the number of colonies was increased in comparison with the control group that had not been tested, which could indicate the high effect of waves on 
microorganisms. However, in both fields with the intensity of 1 and 2 milliseconds and at different frequencies, increasing effect on bacterial growth was observed and with increasing frequency, the effect would be less on the growth of bacteria. In $S$. aureus, ELF-EMF also had an increased effect on bacterial growth, but this value was lower than that of $E$. coli. On the other hand, different frequencies also had no significant effect on bacterial growth, which showed the different effect of magnetic waves on grampositive and Gram-negative bacteria. The reason for this can be the difference in the structure of the cell wall of the gram-positive and gram-negative bacteria. Gram-positive bacteria appear to be less sensitive to magnetic waves due to the high thickness of the cell wall caused by the peptidoglycan layers, while the cell wall and cytoplasmic membrane structure are completely different in gram-negative bacteria such as E. coli. Of course, it should be noted that this is an initial hypothesis, and to prove it, it is necessary to carry out extensive studies and the effect of magnetic waves should be measured on different grampositive and gram-negative bacteria. The results obtained in the present study are in line with the results obtained by Nawrotek and his colleagues. They reported that $E$. coli and $S$. aureus showed increased cell proliferation and survival in the pretreatment with magnetic waves. Therefore, the presence of these bacteria in the vicinity of the magnetic field can make it difficult to treat the diseases caused by these pathogens.

\section{Limitations}

The Electrical devices have a major role in this study were produced by our homemade electromagnetic generator this step is the major limitation in designed of the study.

\section{Abbreviations}

exposure to Low-Frequency Magnetic Fields (ELF-EMF)

\section{Declarations}

\section{Ethics approval and consent to participate}

The study approved in Ethical Committee of Arak University of Medical Sciences and the ethic approval code is IR.ARAKMU.REC.1397.846. Informed consent was obtained from all the participants prior to enrolment.

\section{Consent for publication}

Not Applicable.

\section{Availability of data and material}


Please contact corresponding author (F.S) for data requests.

\section{Competing interests}

The authors declare that they have no conflict of interests.

\section{Funding}

No funding sources used in this study.

\section{Authors' contributions}

All authors read and approved the final manuscript.

\section{Acknowledgments}

The authors would like to thank all friends and colleagues of Arak University of Medical Sciences for their relentless efforts.

\section{References}

1.Lee HC, Hong MN, Jung SH, Kim BC, Suh YJ, Ko YG, et al. Effect of extremely low frequency magnetic fields on cell proliferation and gene expression. Bioelectromagnetics. 2015;36(7):506-16.

2.Ansari RM, Hei TK. Effects of $60 \mathrm{~Hz}$ extremely low frequency magnetic fields (EMF) on radiation- and chemical-induced mutagenesis in mammalian cells. Carcinogenesis. 2000;21(6):1221-6.

3.Martirosyan V, Baghdasaryan N, Ayrapetyan S. Bidirectional frequency-dependent effect of extremely low-frequency electromagnetic field on E. coli K-12. Electromagn Biol Med. 2013;32(3):291-300.

4.Fojt L, Strašák L, Vetterl V, Šmarda J. Comparison of the low-frequency magnetic field effects on bacteria Escherichia coli, Leclercia adecarboxylata and Staphylococcus aureus. Bioelectrochemistry. 2004;63(1):337-41.

5.Samarbaf-Zadeh A, Moosavi R, Tahmasbi-Birgani M, Darki H. THE EFFECT OF STATIC ELECTROMAGNETIC FIELD ON CEPHALOTHIN-RESISTANT PSEUDOMONAS AEROGINOSA. Jundishapur J Nat Pharm Prod. 2006(01):13-7.

6.Inhan-Garip A, Aksu B, Akan Z, Akakin D, Ozaydin AN, San T. Effect of extremely low frequency electromagnetic fields on growth rate and morphology of bacteria. Int J Radiat Biol. 2011;87(12):115561. 
7.Segatore B, Setacci D, Bennato F, Cardigno R, Amicosante G, lorio R. Evaluations of the Effects of Extremely Low-Frequency Electromagnetic Fields on Growth and Antibiotic Susceptibility of Escherichia coli and Pseudomonas aeruginosa. Int J Microbiol. 2012;2012:587293.

8.Babushkina IV, Borodulin VB, Shmetkova NA, Morrison VV, Usanov AD, Skripal' AV, et al. The Influence of Alternating Magnetic Field on Escherichia coli Bacterial Cells. Pharmaceutical Chemistry Journal. 2005;39(8):398-400.

9.Justo OR, Perez VH, Alvarez DC, Alegre RM. Growth of Escherichia coli under extremely low-frequency electromagnetic fields. Appl Biochem Biotechnol. 2006;134(2):155-63.

10.Segatore B, Setacci D, Bennato F, Cardigno R, Amicosante G, lorio R. Evaluations of the effects of extremely low-frequency electromagnetic fields on growth and antibiotic susceptibility of Escherichia coli and Pseudomonas aeruginosa. International journal of microbiology. 2012;2012.

11.Bayatiani M, Seif F, Karbalayi M. Design and Fabrication of a Magnetic Field Generator with Variable Intensity and Frequency for Use in Medical and Biological Studies. Journal of Iranian Clinical Research. 2015(1):1-5.

\section{Figures}

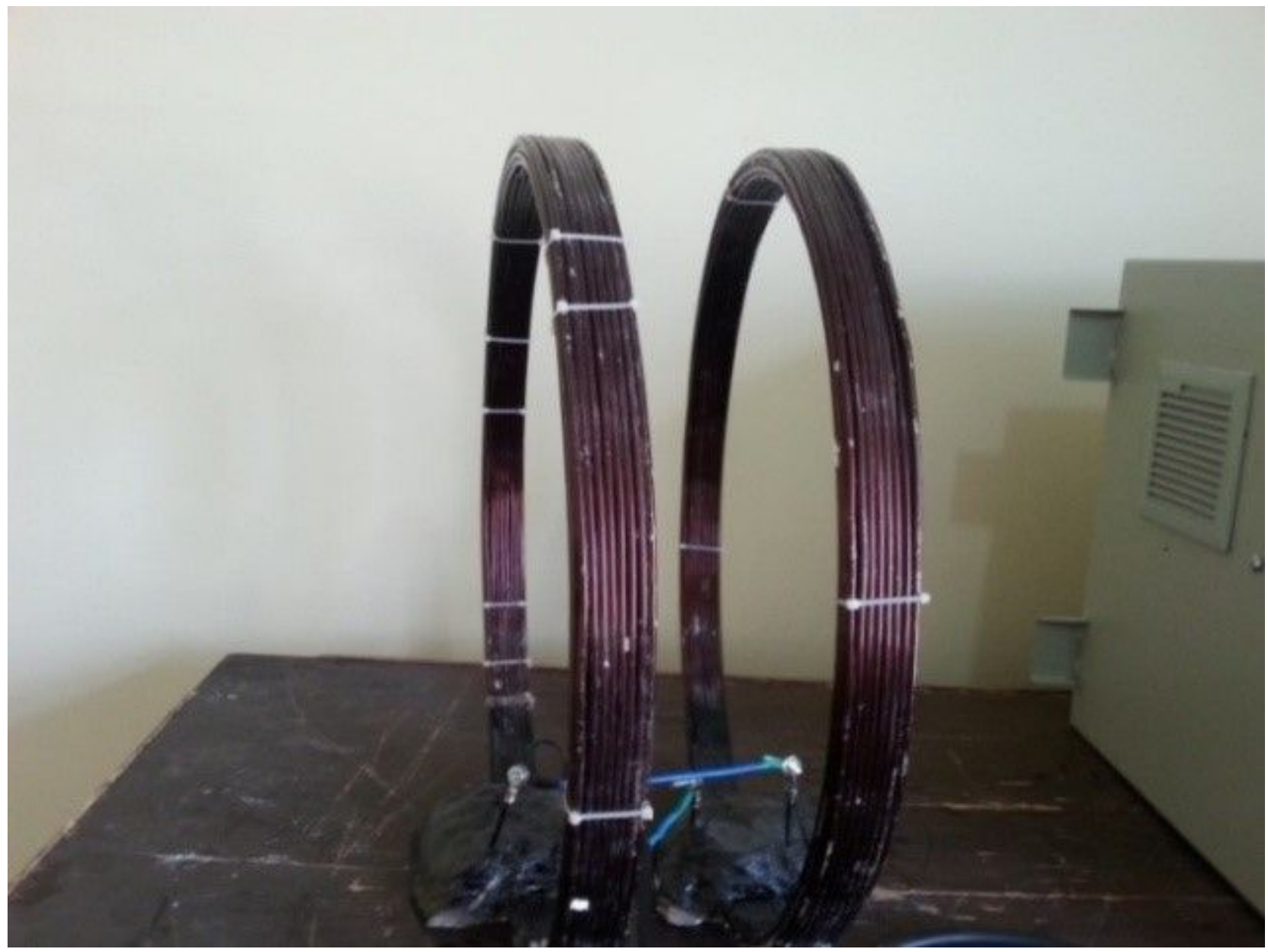


Figure 1

Electromagnetic system

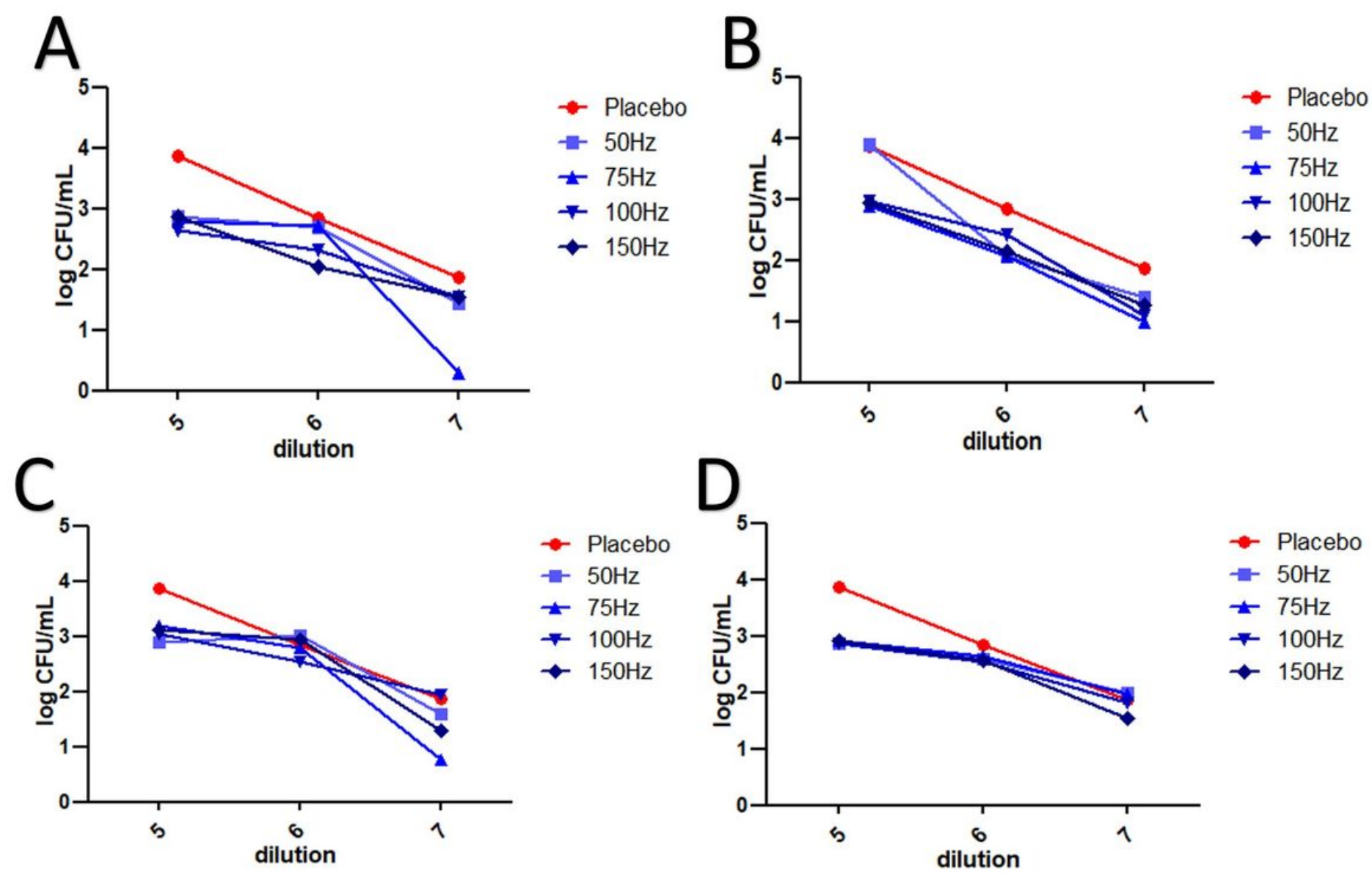

Figure 2

The magnetic (1 MT) fields effect on the bacterium growth on A) E-coli and B) S.aureus The magnetic (2 MT) field's effect on the bacterium growth on C) E-coli and D) S.aureus 